\title{
Perception of Field Veterinary Personnel on Job Stress and Performance: A Ground Level Analysis in Tamil Nadu and Uttar Pradesh States
}

\author{
K. Pachaiyappan ${ }^{1 *}$, Rupasi Tiwari ${ }^{2}$, Mahesh Chander $^{3}$ and B.P. Singh ${ }^{3}$ \\ ${ }^{1}$ SRRC of ICAR - Central Sheep \& Wool Research Institute, Mannavanur, Kodaikanal, Tamil \\ Nadu - 624103, India \\ ${ }^{2}$ I/C ATIC, ICAR-Indian Veterinary Research Institute, Izatnagar, \\ Uttar Pradesh 243122, India \\ ${ }^{3}$ Division of Extension Education, ICAR-Indian Veterinary Research Institute, Izatnagar, \\ Uttar Pradesh 243122, India \\ *Corresponding author
}

\begin{tabular}{|c|c|c|}
\hline & \multicolumn{2}{|l|}{ A B S T R A C T } \\
\hline $\begin{array}{l}\text { Ke y w o r d s } \\
\text { Field veterinarians, } \\
\text { Stress, Job performance, } \\
\text { Coping mechanism }\end{array}$ & \multirow{3}{*}{\multicolumn{2}{|c|}{$\begin{array}{l}\text { The present study, conducted with randomly selected } 60 \text { field veterinarians of Tamil Nadu } \\
\text { and Uttar Pradesh states reveals that, majority of the respondents were men, having } \\
\text { masters' degree, and medium length of service. Majority of the field veterinaries covers a } \\
\text { significant area of jurisdiction amounting to } 25 \text { sq.km serving the veterinary needs of the } \\
\text { farmers by working on and off the office campus. A significant proportion amongst the } \\
\text { respondents perceived their workload at field, as heavy. All of them had training exposure, } \\
\text { medium level of job satisfaction and stress. Good balance diet and proper sleep were their } \\
\text { top two coping mechanisms to overcome stress at job or any given circumstance. Policy } \\
\text { interventions are the need of the hour to reduce the stress level in the field vets ensuring } \\
\text { services properly delivered to the rural needy. }\end{array}$}} \\
\hline Article Info & & \\
\hline $\begin{array}{l}\text { Accepted: } \\
\text { 10 October } 2018 \\
\text { Available Online: } \\
10 \text { November } 2018 \\
\end{array}$ & & \\
\hline Introduction & & $\begin{array}{l}\text { urbanization and rising incomes (Ahuja and } \\
\text { Redmond, 2001). The State Department of }\end{array}$ \\
\hline \multicolumn{2}{|c|}{$\begin{array}{l}\text { Livestock sector provides supplementary } \\
\text { employment and sustainable source of income } \\
\text { to many small and marginal farmers. }\end{array}$} & $\begin{array}{l}\text { Animal Husbandry (SDAH) in the states is the } \\
\text { peak authority to provide necessary inputs in } \\
\text { terms of manpower, policy support and } \\
\text { medicaments with the goal of sustaining and }\end{array}$ \\
\hline \multirow{4}{*}{\multicolumn{2}{|c|}{$\begin{array}{l}\text { The sector is predicted to produce more than } \\
\text { half of the total agricultural output in value } \\
\text { terms and growth in demand for livestock } \\
\text { products is primarily expected to emanate } \\
\text { from the developing countries (like India) due } \\
\text { to human population growth, increasing }\end{array}$}} & further improving the production of livestock \\
\hline & & products. The Department provides \\
\hline & & $\begin{array}{l}\text { comprehensive veterinary assistance and } \\
\text { health cover to all livestock and poultry across }\end{array}$ \\
\hline & & $\begin{array}{l}\text { the States and the main strength of SDAH is } \\
\text { its Veterinary Officers working at field. }\end{array}$ \\
\hline
\end{tabular}


Field Veterinary Officers play a key role in improvising scientific and technological deeds to the livestock farming community by means of health care, prophylaxis and implementation of welfare schemes leading to livelihood security of the rural needy. Stress in general has a great bearing on one's job performance in any field and this is perhaps more in case of Field Veterinarians as perceived in general, thanks to many rural oriented programs being implemented in states during the recent years.

Hence, it is considered worthwhile analyzing the amount of stress, the field Veterinarians experiencing in their place of work and the effect of stress on their job performance, coping strategies adopted by the field level workers and similar other dimension of the matter and with this background the study was proposed and conducted.

\section{Materials and Methods}

Tamil Nadu (TN) and Uttar Pradesh (UP) states were purposively selected to conduct this research. Two districts from each state; Kancheepuram and Villupuram districts in Tamil Nadu \& Bareilly and Budaun districts in Uttar Pradesh were selected for the research. In both Uttar Pradesh and Tamil Nadu, schemes and services by the Animal Husbandry Department of the state government are similar within the states, for both the districts except for few minor differences like work force strength and infrastructure etc.

So, 15 (Fifteen) Veterinary Officers were randomly chosen from each district to collect their views on their job performance, perception, stress etc. and extension services by private livestock input dealers, putting the total number of respondents to 60 . A questionnaire was prepared and circulated amongst them and data was collected at their work places. Variables viz., Age, Gender, Education, Service coverage, Service length, Workload perception, Job satisfaction, Job stress and Job performance etc. were studied.

\section{Results and Discussion}

Table 1 reveals that, majority $(43.3 \%)$ of the field veterinary officers belonged to middle age (36-45 years) followed by young age category $(38.3 \%)$. A slight variation could be seen between the states amongst the young and middle age categories but, the overall count $(86.7 \%$ in Tamil Nadu and $76.7 \%$ in Uttar Pradesh) stands similar exhibiting the availability of young workforce in implementing various schemes and programs as and when announced by the implementing agencies. Majority (83.3\%) of the respondents were males counting the rest 16.7 per cent female field veterinarians, as understood form the table. The table also explains that majority $(48.3 \%)$ of the field veterinarians under study had their jurisdiction up to $25 \mathrm{Sq}$. $\mathrm{km}$ followed by 45 per cent of them having 26-45 sq. km and a small segment of the respondents had to serve limits even more than $45 \mathrm{Sq}$. $\mathrm{km}$ from their workplace.

A wide majority $(60 \%)$ of the field veterinarians had medium level of total service followed by two categories low and high with equal weightage of 20 per cent falling under each the category. The field veterinarians on an average worked 5.75 hours per day in their office and 3. 8 hours away from the office in the field. In case of Tamil Nadu, the figures were 5.8 hours at office and 3.8 hours away whilst in Uttar Pradesh, 5.7 hours in office and 3.8 hours away from the office as seen in table 1. The figures explain that irrespective of the work location the respondents were working on an average of 9.55 hours per day.

Workload refers to the amount of work/labour an individual or a machine/ something has to 
do as desired by the employer. There is a distinction between the actual amount of work and the individual's perception of the workload. Workload can also be classified as quantitative - the amount of work to be done or qualitative - the difficulty of the work (Jex, 1998). Workload perception has been studied with an aim to understand the perceived amount / load of work being carried out by field veterinary officers under five identified categories viz., Very light, Light, Average, Heavy and too Heavy.

It could be observed from table 1 that majority $(46.7 \%)$ of the field veterinarians perceived that the workload in their organization was Heavy, followed by Average (28.3\%) and rest 25 per cent of them had opined that the workload in their organization was too heavy.

There happens to be a deviation in the values amongst the states. In Tamil Nadu, a bigger proportion $(40+33.3 \%)$ opined that the workload was Heavy / Too heavy whilst in Uttar Pradesh, a significant proportion $(56.7+30 \%)$ expressed their workload as Heavy to Average.

This difference could be due to many government sponsored people welfare free schemes undertaken in Tamil Nadu like free milch cattle distribution to rural women, free goat distribution to rural women, livestock insurance etc.

Table 1 also shows that more than half (63.3 $\%$ ) of the field veterinarians had medium level of job satisfaction compared to 23.3 per cent with high job satisfaction and 13.3 per cent with low job satisfaction at their work. The findings are in accordance with the findings of Gautam et al., (2006) who had reported that just more than half of the respondents had medium level of job satisfaction at their workplaces. More opportunities for career development, trainings undergone, masters' degree expertise and varietal job accomplishments than any other veterinary contemporaries might be the reasons for job satisfaction.

Stress is a complex entity with varied causative factors like personal, familial, and job. The severity of stress will vary from person to person. The table implies that almost half $(51.7 \%)$ of the respondents, had medium level of stress experienced / underwent in their professional and personal life followed by low level $(25 \%)$ and high level of stress by 23.3 per cent of the field veterinarians as estimated form their responses.

Number of respondents falling under medium category between the states; were found to be similar but there is a small difference in numbers and proportion of respondents having low and high levels of stress might be attributed to the comparatively higher number of welfare schemes and programs happening in Tamil Nadu animal husbandry sector.

In general observation and conversation, it could be decided that lack of sufficient time for personal work and unfulfilled commitments by the veterinary officers, inability to spend enough time with family, distance of working institution from home, lack of sufficient skilled supporting staff and too heavy workload might be the reasons for the stress experienced by the respondents in both the states.

Park (2007) argues that the negative implications of work stress are recognized as a challenge to both employers and workers, with women, youth, shift, part-time, and non-white collar workers being more likely to have highstrain jobs. Those with such jobs perceived their work to be physically demanding and less satisfying. Low personal incomes and low levels of education were also associated with higher stress. 
Table.1 Parameters and their measurements pertinent to field veterinary personnel

\begin{tabular}{|c|c|c|c|}
\hline Description & Tamil Nadu $n=30$ & Uttar Pradesh $n=30$ & Total $\mathrm{N}=60$ \\
\hline \multicolumn{4}{|c|}{ Age (in years) } \\
\hline Up to 35 (Young) & $17(56.7)$ & $6(20.0)$ & $23(38.3)$ \\
\hline 36 to 45 (Middle) & $9(30.0)$ & $17(56.7)$ & $26(43.3)$ \\
\hline 46 and above (Old) & $4(13.3)$ & $7(23.3)$ & $11(18.3)$ \\
\hline \multicolumn{4}{|c|}{ Gender (Descriptive) } \\
\hline Male & $24(80.0)$ & $26(86.7)$ & $50(83.3)$ \\
\hline Female & $6(20.0)$ & $4(13.3)$ & $10(16.7)$ \\
\hline \multicolumn{4}{|c|}{ Service coverage } \\
\hline Up to 25 sq. $\mathrm{km}$ & $18(60)$ & $11(36.5)$ & $29(48.3)$ \\
\hline 26-45 sq. km & $10(33.5)$ & $17(57)$ & $27(45)$ \\
\hline More than 45 sq. $\mathrm{km}$ & $2(6.5)$ & $2(6.5)$ & $4(6.7)$ \\
\hline \multicolumn{4}{|c|}{ Time spent for work } \\
\hline In the office & 5.8 hours & 5.7 hours & 5.75 hours \\
\hline Away from the office & 3.8 hours & 3.8 hours & 3.8 hours \\
\hline Total (hours / day) & 9.6 hours & 9.5 hours & 9.55 hours \\
\hline \multicolumn{4}{|c|}{ Length of service (Years) } \\
\hline Low & $7(23.3)$ & $5(16.7)$ & $12(20.0)$ \\
\hline Medium & $15(50.0)$ & $21(70.0)$ & $36(60.0)$ \\
\hline High & $8(26.4)$ & $4(13.3)$ & $12(20.0)$ \\
\hline \multicolumn{4}{|c|}{ Workload perception (Perception Score) } \\
\hline Average & $8(26.7)$ & $9(30)$ & $17(28.3)$ \\
\hline Heavy & $12(40)$ & $16(56.7)$ & $28(46.7)$ \\
\hline Too heavy & $10(33.3)$ & $5(13.3)$ & $15(25)$ \\
\hline \multicolumn{4}{|c|}{ Job satisfaction (Perception Score) } \\
\hline Low & $8(26.7)$ & $6(20)$ & $14(23.3)$ \\
\hline Medium & $18(60)$ & $20(66.7)$ & $38(63.3)$ \\
\hline High & $4(13.3)$ & $4(13.3)$ & $8(13.3)$ \\
\hline \multicolumn{4}{|c|}{ Job stress (Perception Score) } \\
\hline Low stress (up to 45) & $6(20)$ & $9(30)$ & $15(25)$ \\
\hline Medium stress(46 -59) & $16(53.3)$ & $15(50)$ & $31(51.7)$ \\
\hline $\begin{array}{l}\text { High stress (more than } \\
\text { 60) }\end{array}$ & $8(26.7)$ & $6(20)$ & $14(23.3)$ \\
\hline
\end{tabular}


Table. 2 Stress coping strategies followed by the respondents

\begin{tabular}{|l|l|l|l|l|l|l|l|}
\hline $\begin{array}{l}\text { S } \\
\text { no }\end{array}$ & Coping strategies & $\begin{array}{l}\text { TN } \\
\text { Sco }\end{array}$ & $\begin{array}{l}\text { TN } \\
\text { Rank }\end{array}$ & $\begin{array}{l}\text { UP } \\
\text { Sco }\end{array}$ & $\begin{array}{l}\text { UP } \\
\text { Rank }\end{array}$ & $\begin{array}{c}\text { Cumulat } \\
\text { ive }\end{array}$ & Rank \\
\hline 1. & Good balanced diet & 141 & 1 & 125 & 1 & 266 & 1 \\
\hline 2. & Proper sleep & 112 & 2 & 116 & 2 & 228 & 2 \\
\hline 3. & $\begin{array}{l}\text { Seek social support (Friends, family } \\
\text { members, colleagues) }\end{array}$ & 98 & 3 & 105 & 4 & 203 & 3 \\
\hline 4. & Physical exercises & 95 & 5 & 103 & 3 & 198 & 4 \\
\hline 5. & $\begin{array}{l}\text { Adopt a hobby (participate in } \\
\text { enjoyable activities) }\end{array}$ & 96 & 4 & 100 & 5 & 196 & 5 \\
\hline 6. & Pre-planning of the job to be done & 80 & 6 & 83 & 6 & 163 & 6 \\
\hline 7. & Meditation / Yoga & 73 & 7 & 76 & 7 & 149 & 7 \\
\hline 8. & Drinking, smoking & 65 & 8 & 76 & 7 & 141 & 8 \\
\hline 9. & Recreational sports & 53 & 9 & 60 & 9 & 113 & 9 \\
\hline 10. & Take a vacation & 30 & 10 & 39 & 10 & 69 & 10 \\
\hline 11. & Counselling \& psychotherapy & 30 & 10 & 30 & 11 & 60 & 11 \\
\hline 12. & $\begin{array}{l}\text { Empty chair technique-Assuming the } \\
\text { persons in front and scolding to }\end{array}$ & 10 & 12 & 14 & 12 & 24 & 12 \\
reduce anger & & & & & & \\
\hline 13. & Use stress antidotes/medical care & 6 & 13 & 7 & 13 & 13 & 13 \\
\hline 14. & $\begin{array}{l}\text { Pillow hit technique-Hitting the } \\
\text { pillow to reduce anger }\end{array}$ & 0 & 14 & 8 & 14 & 8 & 14 \\
\hline
\end{tabular}

Results from the table 2 show that good balanced diet had been ranked first and foremost coping mechanism followed by majority of the respondents. Proper sleep, seeking social support, physical exercises, hobbies and preplanning were ranked as second, third, fourth, fifth and sixth respectively. This might be due to the fact that these are the most common mechanisms adopted to overcome stress. These are the functional or positive coping mechanisms, which can lead to creativity, effectiveness and better adjustment to work life. The results are in support with the findings of Lakshmi (1997) and Annapurna (1998).

It could be observed that meditation / yoga and related techniques have been ranked as seventh mechanism among the respondents. Drinking and smoking and recreational activities have been given eighth and ninth spots whilst tenth position had been acquired by vacation. Sports and taking vacation to cope up the stress were not followed by many of the respondents. Lack of time might be the reason for the seen trend. It was also observed that empty chair and pillow hitting techniques were ranked as twelfth and fourteenth spots, which might be due to the fact that these mechanisms had not reached the field veterinarians. It is to be noted that the use of stress antidotes / medical care, counseling and psychotherapy; which are of dysfunctional style or negative coping mechanisms, were followed by very less number of respondents which is a good indication of wellness among the veterinarians.

In Conclusion, Stress in job and family is an inevitable component. The effect it alters the 
workability of the individuals matters a lot in terms of performance and organizations' growth. The present study concludes that the field veterinarians succumb to stress owing to the work load and jurisdictions. As the central and state governments have strengthened their focus towards animal husbandry related programs, the stress factor in field veterinary officers will have a paved increment which in turn would have implications on performance and thereby hindering the services to be rendered by the governments to the rural society. Policy interventions are the need of the hour to take actions to reduce the stress levels for the field level officers and this could be attempted by increasing the manpower, shared responsibilities and roping in private players to the channel of work. Field veterinary officers must be aware of their own feeling and physical conditions to realize problems that had existed to seek proper coping strategy.

\section{Acknowledgements}

This article is from a part of $\mathrm{PhD}$ research by the first author. The authors would like to thank the Director and Joint Directors of ICAR-Indian Veterinary Research Institute, Izatnagar for having provided permission and infrastructural/logistical facilities to successfully carryout the research work.

\section{References}

Ahuja, Vinod and Elizabeth Redmond. 2001. Economic and Policy Issues in Livestock Service Delivery to the Poor. Background paper for the FAO project memorandum "Pro-Poor Livestock Policy Initiative: Fostering the Policy Dialogue in Support of Equitable, Safe and Clean Livestock Farming"

Annapurna, R.P 1998. Organizational Role Stress and Job Performance of Teachers in ANGRAU. Unpublished M.Sc, (Ag.) Thesis, Acharya N.G Ranga Agricultural University, Hyderabad.

Gautam, M.K. Mandal and R.S. Dalal 2006. Job Satisfaction of Faculty Members of Veterinary Sciences: An Analysis. Livestock Research for Rural Development, 18(6).

Jex, S. M. 1998. Stress and job performance: Theory, research, and implications for managerial practice. Thousand Oaks, CA: Sage.

Lakshmi, T. and P. Venkataramaiah 2003. Impact of Stressful Events in the Past One-year on Behavior of Researchers and Agricultural Officers. Journal of Research ANGRAU, 31(2): 64 - 69.

Park, Jungwee. 2007. Work stress and job performance. Perspectives. Statistics Canada-Catalogue no. 75-001-XIE

\section{How to cite this article:}

Pachaiyappan, K., Rupasi Tiwari, Mahesh Chander and Singh, B.P. 2018. Perception of Field Veterinary Personnel on Job Stress and Performance: A Ground Level Analysis in Tamil Nadu and Uttar Pradesh States. Int.J.Curr.Microbiol.App.Sci. 7(11): 1094-1099. doi: https://doi.org/10.20546/ijcmas.2018.711.127 